\title{
CARBON CATABOLITE REGULATION OF GENTAMICIN FORMATION
}

\author{
Laura Escalante, Rina Gonzalez, Ana-Maria Obregon and Sergio Sanchez* \\ Departamento de Biotecnologia del Instituto de Investigaciones Biomedicas, \\ Universidad Nacional Autonoma de Mexico, \\ Mexico D.F. 04510, Mexico \\ (Received for publication June 24, 1991)
}

\begin{abstract}
The effect of utilizable carbon sources on the production of gentamicin by Micromonospora purpurea has been studied. High D-glucose and D-xylose concentrations $(40 \mathrm{mg} / \mathrm{ml})$, exerted a strong and permanent negative action on antibiotic formation. On the other hand, similar concentrations of $\mathrm{D}$-fructose, D-mannose, maltose and starch caused no effect. The glucose action is seen only if added during the logarithmic growth phase; moreover, the sugar needs to be metabolized to show its negative effect.
\end{abstract}

Gentamicin is a complex of aminocyclitol compounds produced under aerobic conditions by some species of Micromonospora. The complex consists of three major compounds referred to as $\mathrm{C} 1, \mathrm{Cla}$ and C2, highly active against Gram-negative bacteria and Mycobacterium tuberculosis ${ }^{1}$. As with other aminocyclitol antibiotics, gentamicin is synthesized from 2-deoxystreptamine ${ }^{2)}$, probably through a branched biosynthetic pathway, as suggested from biotransformation experiments using idiotrophic mutants of Micromonospora purpurea ${ }^{3}$. Little information is available with respect to the fermentative production of gentamicin by $M$. purpurea and the factors and conditions that control its biosynthesis.

The negative influence exerted by the type and concentration of the carbon source on the fermentative production of secondary metabolites, has been well documented for several antibiotics ${ }^{4}$. Although the pattern of carbohydrate utilization by $M$. purpurea has been established ${ }^{5\rangle}$, there is no information concerning the influence of the carbon source on antibiotic formation. In this paper we report of the effect of utilizable carbon sources on growth and gentamicin biosynthesis in this actinomycete.

\section{Materials and Methods}

Microorganism and Cultivation

Micromonospora purpurea NRRL-2953 was kindly supplied by the ARS Culture Collection, U.S. Department of Agriculture, Peoria, IL., U.S.A.

Spores of this microorganism were obtained from slants containing $0.5 \mathrm{~g}$ yeast extract, $0.5 \mathrm{~g}$ casein hydrolysate, $0.1 \mathrm{~g}$ calcium carbonate, $2.0 \mathrm{~g}$ starch, $1.0 \mathrm{~g}$ glucose $(\mathrm{pH} 7.6)$ and $1.5 \mathrm{~g}$ agar per $100 \mathrm{ml}$ distilled water. They were maintained at $-20^{\circ} \mathrm{C}$ in $2 \mathrm{ml}$ vials containing $1 \mathrm{ml}$ of a mixture consisting of $40 \%$ glycerol, $1 \%$ malt extract and $0.4 \%$ yeast extract. For seed culture, approximately $10^{6} \mathrm{M}$. purpurea spores (from a 5-day old slant) were inoculated into a $50-\mathrm{ml}$ Erlenmeyer flask containing $10 \mathrm{ml}$ of the following medium: $0.3 \mathrm{~g}$ beef extract, $0.5 \mathrm{~g}$ Tryptone, $0.5 \mathrm{~g}$ yeast extract, $0.4 \mathrm{~g}$ calcium carbonate, $0.1 \mathrm{~g}$ glucose and $2.4 \mathrm{~g}$ starch (pH 7.6) per $100 \mathrm{ml}$ distilled water. Incubations were carried out at $29^{\circ} \mathrm{C}$ for 60 hours on a rotary shaker $(175 \mathrm{rpm})$. For antibiotic production, $2 \mathrm{ml}$ of the above culture were inoculated into $250 \mathrm{ml}$ Erlenmeyer flasks containing $50 \mathrm{ml}$ of the chemically defined medium reported by CARvaJAL (U.S. Patent 2,808,364, 1957) supplemented with $0.004 \mathrm{mM} \mathrm{CoCl}_{2} \cdot 6 \mathrm{H}_{2} \mathrm{O}$. After preparation, the medium was adjusted to $\mathrm{pH} 7.0$ and sterilized. Carbohydrates were sterilized separately and added before inoculation. Fermentations were carried out at $29^{\circ} \mathrm{C}$ for 7 days on a rotary shaker at $175 \mathrm{rpm}$.

Assay of Gentamicin

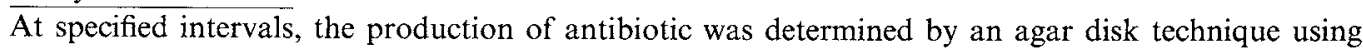


Bacillus subtilis ATCC 6633 as the assay organism ${ }^{6}$. After incubation ( 36 hours at $29^{\circ} \mathrm{C}$ ) in a bioassay medium containing $0.5 \mathrm{~g}$ yeast extract, $1.0 \mathrm{~g}$ Tryptone, $0.5 \mathrm{~g} \mathrm{NaCl}$ and $1.0 \mathrm{~g}$ agar per $100 \mathrm{ml}$ distilled water, $\mathrm{pH} 7.0$, zones of inhibition were measured and the amount of gentamicin estimated using gentamicin sulfate (Sigma Chemical Co., St. Louis, MO) as standard.

\section{Growth Determination}

Samples of mycelia were harvested, washed with 2 vol distilled water and placed in $2 \mathrm{ml}$ of $0.3 \mathrm{M}$ trichloroacetic acid. After centrifugation, the pellet was resuspended in $1 \mathrm{ml}$ of $0.4 \mathrm{~N} \mathrm{NaOH}$, and its protein concentration determined by the Lowry method using bovine serum albumin as standard ${ }^{7}$.

\section{Reproducibility of Results}

The experiments reported were repeated at least twice (two independent experiments) and the results reported are the mean values. The observed variations were consistently less than $10 \%$.

\section{Results}

\section{Effect of Glucose Concentration on Fermentations}

M. purpurea was able to utilize glucose as the only carbon source for growth and gentamicin formation. Fig. 1 shows maximum growth and specific antibiotic production of this microorganism in fermentations with glucose concentrations ranging from 1 to $50 \mathrm{mg} / \mathrm{ml}$. As seen in the figure, growth of the culture increases in proportion to the sugar concentration added to the fermentation medium (up to $15 \mathrm{mg} / \mathrm{ml}$ ). Plots of growth versus time gave profiles showing an increase in the extent of growth but not in the culture growth rate (not shown). In regard to specific gentamicin formation, an inverse correlation was found between the maximum antibiotic produced and the initial carbohydrate concentration added to the fermentation medium, with a maximum effect seen at $50 \mathrm{mg} / \mathrm{ml}$ (Fig. 1). As shown, only slight differences were observed in the medium $\mathrm{pH}$ at all sugar concentrations tested, excluding this possibility as the cause of gentamicin repression.

Differential Rate of Antibiotic Synthesis

To gain more information about the carbohydrate effect, $M$. purpurea was grown with low $(10 \mathrm{mg} / \mathrm{ml})$ and high $(40 \mathrm{mg} / \mathrm{ml})$ glucose concentrations, and growth was plotted versus antibiotic production at different times during the fermentation. As can be seen in Fig. 2, all differential antibiotic rate values in the high sugar fermentations were reduced approximately by one half in comparison to those obtained with the lower glucose concentration. In other words, the use of high glucose resulted in an increase of growth but a reduction in the slope of antibiotic production.

Fig. 1. Effect of different D-glucose concentrations on the maximum growth $(\triangle)$, gentamicin formation $(\square)$, final $\mathrm{pH}$ of the medium $(\bullet)$, and specific gentamicin formation $(0)$.

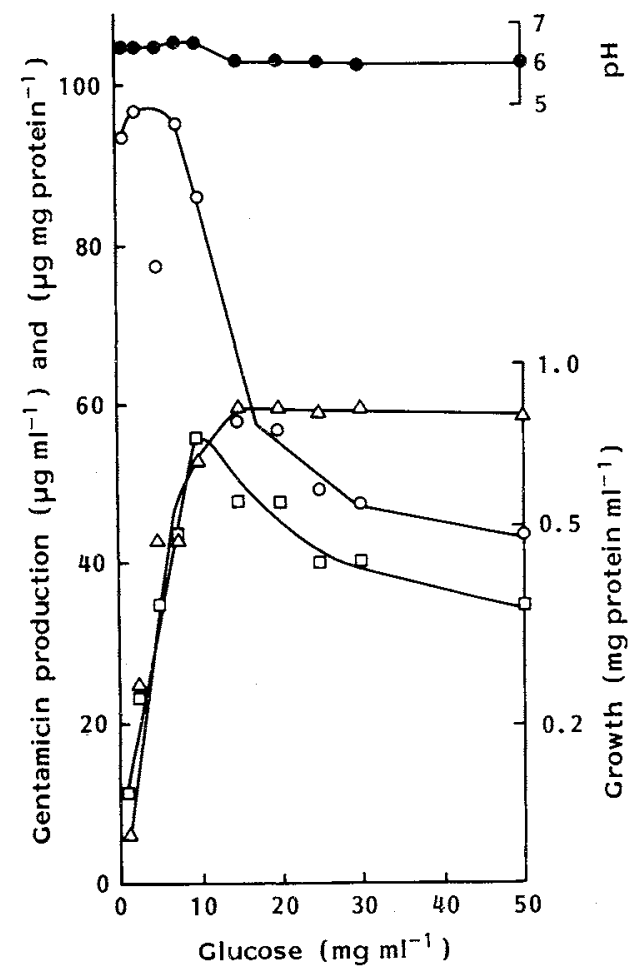


Fig. 2. Effect of D-glucose on differential rate of gentamicin formation.

Cultures were grown in fermentation medium with D-glucose $10(0)$ or $40(\Delta) \mathrm{mg} / \mathrm{ml}$.

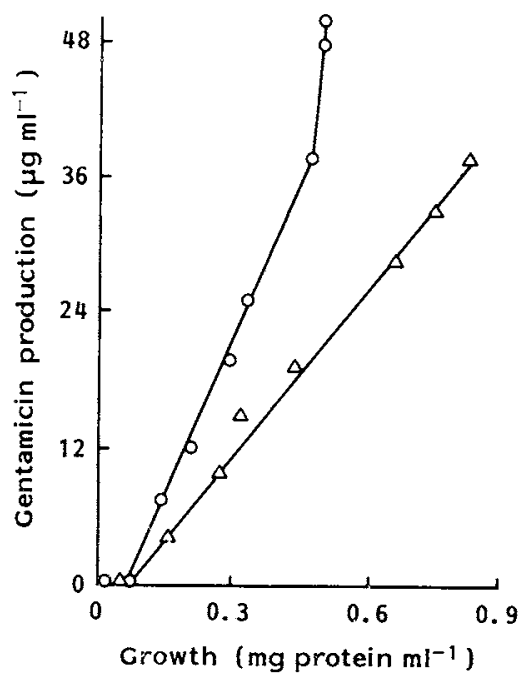

Table 1. Effect of 2-deoxyglucose on maximum growth and gentamicin formation.

\begin{tabular}{|c|c|c|c|c|}
\hline \multirow{2}{*}{ Condition } & \multirow{2}{*}{$\begin{array}{l}\text { Time of } \\
\text { addition } \\
\text { (hours) }\end{array}$} & \multirow{2}{*}{$\begin{array}{l}\text { Growth } \\
(\mathrm{mg} / \mathrm{ml})\end{array}$} & \multicolumn{2}{|c|}{ Antibiotic } \\
\hline & & & $\mu \mathrm{g} / \mathrm{ml}$ & $\begin{array}{l}\mu \mathrm{g} / \mathrm{mg} \\
\text { protein }\end{array}$ \\
\hline Control & & 0.5 & 48 & 96 \\
\hline D-Glucose & 48 & 0.96 & 30 & 31 \\
\hline 2-Deoxyglucose & 48 & 0.16 & 16 & 100 \\
\hline D-Glucose & 72 & 0.8 & 22 & 27 \\
\hline 2-Deoxyglucose & 72 & 0.35 & 28 & 80 \\
\hline
\end{tabular}

Cells were grown with $1 \%$ glucose and at specified intervals $3 \%$ glucose or 2-deoxyglucose was added to the fermentation: Cultures were incubated for 168 hours at $29^{\circ} \mathrm{C}$.
Fig. 3. Effect of the time of D-glucose addition on gentamicin production.

The carbohydrate was added at $0(\bullet), 24(\triangle), 48$ $(\Delta), 60(\square)$ and 96 hours (घ) fermentations. Control (O) without further feeding.

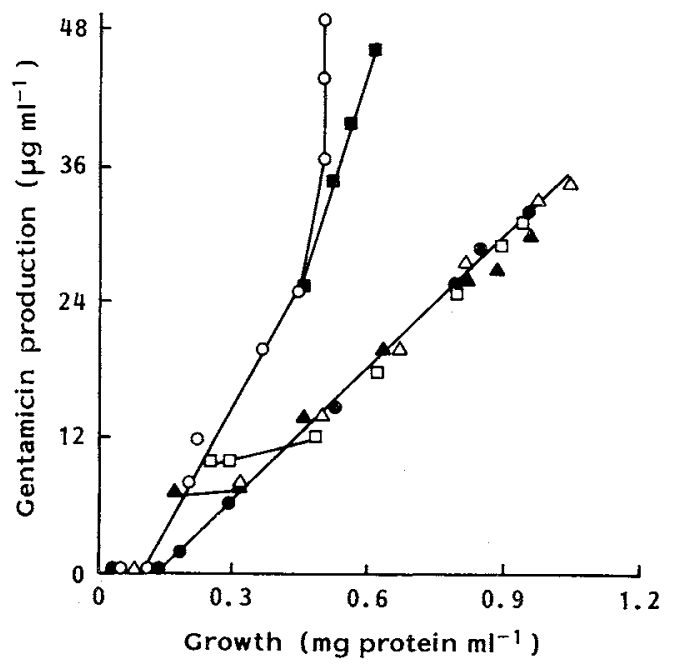

Table 2. Effect of different carbohydrates on gentamicin formation

\begin{tabular}{lrrrr}
\hline & \multicolumn{4}{c}{$\begin{array}{c}\text { Specific antibiotic formation } \\
\text { Carbon }\end{array}$ source } \\
\cline { 2 - 5 } & \multicolumn{4}{c}{ Carbohydrate concentration $(\mathrm{mg} / \mathrm{ml})$} \\
& 5.0 & 10.0 & 20.0 & 40.0 \\
\hline D-Glucose & 97.5 & 74.5 & 50.5 & 34.0 \\
D-Xylose & 107.5 & 86.5 & 34.0 & 0.0 \\
D-Fructose & 182.5 & 190.0 & 147.0 & 151.5 \\
D-Maltose & 31.0 & 34.0 & 24.0 & 36.0 \\
D-Mannose & 44.5 & 40.5 & 46.0 & 46.0 \\
Sucrose & 103.5 & 103.0 & 63.0 & 69.5 \\
Starch & 47.0 & 38.0 & 36.0 & 48.0 \\
\hline
\end{tabular}

After 96 hours incubation, gentamicin was determined in the fermentation broths.

\section{Addition of D-Glucose during the Fermentation}

In order to characterize the glucose effect, the carbohydrate was added at different times during fermentation, to cultures growing with a low glucose concentration $(10 \mathrm{mg} / \mathrm{ml})$. As seen in Fig. 3, in contrast to the control without additional glucose, the addition of $40 \mathrm{mg} / \mathrm{ml} \mathrm{D}$-glucose at the beginning of the fermentation, or during the first 6 hours of the growth phase, reduced by approximately one half the differential rate of antibiotic biosynthesis. On the other hand, no significant changes were found when the carbohydrate was added to cultures at 96 hours.

\section{Effect of a Glucose Analogue on Antibiotic Formation}

To establish whether or not glucose per se or a metabolite was responsible for this effect, a 
non-metabolizable analogue (2-deoxyglucose), was supplied to cultures grown with a low sugar concentration $^{8)}$. As revealed in Table 1, although growth was severely affected by the analogue addition, only minor changes were observed on specific antibiotic formation, as compared to cultures without it. On the other hand, $40 \mathrm{mg} / \mathrm{ml}$ D-glucose reduced specific gentamicin formation by $70 \%$. Similar observations were obtained from plots of this data, showing the differential rate of antibiotic production i.e. that analogue affected growth but not antibiotic production.

\section{Effect of Other Carbohydrates on Antibiotic Formation}

In addition to D-glucose, D-xylose also exerted a negative effect on gentamicin biosynthesis (Table 2). On the other hand, fructose, maltose, mannose and starch had no influence whereas sucrose showed only a slight one.

\section{Addition of Precursors of the Antibiotic Pathway}

In order to define the step in antibiotic formation that is affected by glucose, we treated reppressed cultures with several precursors and intermediates of the gentamicin pathway in an attempt to reverse the negative action. L-Glutamate, L-glutamine, D-glucosamine and 2-deoxystreptamine (ranging from 1 to $10 \mathrm{~mm}$ ) were employed for this purpose. However, although these compounds were efficiently taken up by the cells, none of these was able to overcome the negative action of the high glucose concentration when added during or at the end of the logarithmic growth phase.

\section{Discussion}

The effect of utilizable carbon sources on the production of gentamicin by $M$. purpurea has been studied. An inverse correlation was found between the maximum antibiotic produced and the initial glucose and xylose concentration added to the fermentation medium. Other carbohydrates such as fructose, maltose, mannose and starch caused no repression. Considering that D-xylose is a precursor of the gentamicin moiety ${ }^{9}$, its negative influence on antibiotic biosynthesis is unexpected. Plots of growth versus antibiotic production in low and high glucose concentrations gave profiles comparable to the catabolite repression of $\beta$-galactosidase elicited by glucose in Escherichia coli ${ }^{10}$. As pointed out by these authors, such an effect is characterized by a strong and permanent negative action on the formation of a given metabolite. Therefore, the possibility of a catabolite repression exerted by D-glucose was considered as the cause of its negative action on antibiotic formation. In agreement with this hypothesis it was found that: a) the carbohydrate influences antibiotic formation only if added during the stage of active protein synthesis; $b$ ) is characterized by a strong and permanent negative effect on the synthesis of gentamicin and c) D-glucose needs to be metabolized to exhibit its negative action on antibiotic formation. Finally, the regulation observed seems to take place at a step beyond the intemediate 2-deoxystreptamine.

\section{Acknowledgments}

This work was partially supported by the CONACyT grant IVT/QF/ NAL/84/2228. We thank Dr. A. SAтоH from the Meiji Seika Kaisha, Ltd., Odawara, Japan, for the 2-deoxystreptamine gift.

\section{References}

1) Wagman, G. H. \& M. J. Weinstein: Antibiotics from Micromonospora. Annu. Rev. Microbiol. 34: 537 557, 1980

2) Pearce, C. J. \& K. L. Rinehart, Jr.: Biosynthesis of amino-cyclitol antibiotics. In Antibiotics. IV. Biosynthesis. Ed., J. W. CorCoran, pp. $74 \sim 100$, Springer-Verlag, 1981

3) Testa, R. T. \& B. C. Tilley: Biotransformation, a new approach to aminoglycoside biosynthesis. I. Sisomicin. J. Antibiotics 28: $573 \sim 576,1975$

4) Hu, W.-S.; A. F. BRANA \& A. L. Demain: Carbon source regulation of cephem antibiotic production by resting 
cells of Streptomyces clavuligerus and its reversal by protein synthesis inhibitors. Enzyme Microb. Technol. 6 : $155 \sim 160,1984$

5) Kawamoto, I.; T. OKa \& T. Nara: Carbon and nitrogen utilization by Micromonospora strains. Agric. Biol. Chem. 47: $203 \sim 215,1983$

6) Sanchez, S.; R. C. Mateos, L. Pantagua, F. Lara \& J. Mora: Nitrogen regulation of penicillin G production in Penicillium chrysogenum. In Advances in Biotechnology. III. Fermentation Products. Eds., M. Moo-YounG \& C. Vezina, pp. 147 154, Pergamon Press, 1981

7) Lowry, O. H.; N. J. Rosebrough, A. L. FarR \& R. J. Randall: Protein measurement with the folin phenol reagent. J. Biol. Chem. 193: 265 275, 1951.

8) EscAlante, L.; H. Lopez, R. C. Mateos, F. LARA \& S. SANChez: Transient repression of erythromycin formation in Streptomyces erythraeus. J. Gen. Microbiol. 128: $2011 \sim 2015,1982$

9) Rinehart, K. L., Jr. \& R. M. Stroshane: Biosynthesis of aminocyclitol antibiotics. J. Antibiotics 29: $319 \sim 353,1976$

10) TYLeR, B.; W. F. LoOMIS, Jr. \& B. MAGASANIK: Transient repression of the lac operon. J. Bacteriol. 94: 2001 2011, 1967 